\title{
BIOLOGIA DA POLINIZAÇÃO DE Jacaratia Spinosa (AUBL) ADC. (CARICACEAE) EM MATA RESIDUAL DO SUDESTE BRASILEIRO
}

\author{
PIRATELLI, A. J., ${ }^{1}$ PINAA-RODRIGUES, F. C. M., ${ }^{2}$ GANDARA, F. B., ${ }^{3}$ SANTOS, E. M. G. ${ }^{4}$ e \\ COSTA, L. G. S. ${ }^{5}$ \\ ${ }^{1}$ Departamento de Ciências Naturais/CEUL, Universidade Federal de Mato Grosso do Sul, \\ C.P. 210, CEP 79600-000, Três Lagoas, MS \\ ${ }^{2}$ Departamento de Silvicultura/IF, Universidade Federal Rural do Rio de Janeiro, Seropédica, RJ \\ ${ }^{3}$ Departamento de Biologia Vegetal/IB, Universidade Estadual de Campinas, Campinas, SP \\ ${ }^{4}$ Departamento de Genética/ESALQ, Universidade de São Paulo, Piracicaba, SP \\ ${ }^{5}$ Departamento de Silvicultura, Faculdade de Ciências Agrárias do Pará, Belém, PA \\ Recebido em 10/09/97 - Aceito em 13/07/98 - Distribuído em 30/11/98
}

(Com 4 figuras)

\author{
ABSTRACT \\ Pollination biology of Jacaratia spinosa (AUBL) ADC. (CARICACEAE) \\ in a residual forest in southwest Brazil
}

The pollination biology of Jacaratia spinosa (Aubl) ADC. (Caricaceae) was studied in Mata de Santa Genebra, Campinas municipality, São Paulo state, Brazil $\left(20^{\circ} 54^{\prime} \mathrm{S} ; 4^{\circ} 05^{\prime} \mathrm{W}\right)$. Data from floral anthesis, nectar volume and sugar concentration, pollen viability, stigma receptivity, location of scent glands, reproduction systems and main visitors/potential pollinators were obtained. The species is dioicious and the masculine plants flourish for a larger period (52 days) than the feminine ones (22 days). Most of the flowers has night anthesis, lasting the masculine ones about 24 hours and the feminine ones, 48 hours. The masculine ones produce on the average, 112,5 $\mathrm{ml}$ of nectar and sugar concentration of $13,9 \%$. The feminine ones didn't produce nectar, having been identified mimetism of the masculine ones by the feminine ones. The pollen viability didn't vary along the day (average $97,20 \%)$. There was production of fruits for agamospermy and for crossed fecundation. The main observed pollinators was moths, what corroborates with its characteristics of phalenophily syndrome; other insects meantime, as butterflies, also can contribute to its reproduction.

Key words: Caricaceae, dioicism, Jacaratia, pollination.

\section{RESUMO}

A biologia da polinização de Jacaratia spinosa (Aubl) ADC. (Caricaceae) foi estudada na Mata de

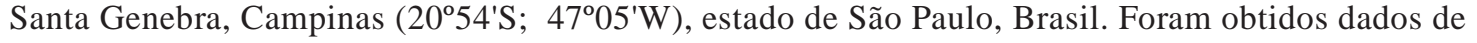
antese floral, volume e concentração de açúcar no néctar, viabilidade do pólen, receptividade do estigma, localização de glândulas de odor, sistemas de reprodução e principais visitantes/potenciais polinizadores. A espécie é dióica e as plantas masculinas florescem por um período maior (52 dias) que as femininas (22 dias). A maioria das flores tem antese noturna, durando as masculinas cerca de 24 horas e as femininas, 48 horas. As masculinas produzem, em média, 112,5 ml de néctar e concentração de açúcar de 13,9\%. As femininas não produzem néctar, tendo sido identificado mimetismo das masculinas pelas femininas. A viabilidade do pólen não variou ao longo do dia (média 97,20\%). Houve produção de frutos por agamospermia e por fecundação cruzada. Os principais polinizadores observados foram mariposas, o que corrobora com suas características de síndrome de falenofilia, havendo, entretanto, outros insetos, como borboletas, que podem contribuir para sua reprodução.

Palavras-chave: Caricaceae, dioicismo, Jacaratia, polinização. 


\section{INTRODUÇÃO}

A fecundação cruzada obrigatória é o modo de reprodução predominante nas comunidades vegetais tropicais (Zapata \& Arroyo, 1978; Bawa, 1979), sendo que $76 \%$ das espécies arbóreas apresentam este tipo de reprodução, ocorrendo o dioicismo em 22\% delas (Bawa, 1974). Em relação ao agente polinizador, predomina a zoofilia nas espécies arbóreas, sendo os insetos os principais polinizadores das dióicas (Croat, 1979; Bawa, 1980b).

A associação entre o modo de reprodução e o papel da planta no processo sucessional é uma excelente ferramenta a ser utilizada em programas de manejo e recuperação de áreas degradadas. Particularmente, no caso das espécies pioneiras dióicas, estes aspectos são cruciais para o entendimento de como estas populações ocupam áreas fragmentadas e recém-colonizadas.

As plantas pioneiras são capazes de ocupar áreas recém-perturbadas, onde as condições de luz, solo e temperatura favorecem a germinação de suas sementes (Martinez-Ramos, 1985). A questão levantada é como estas espécies, que antes não existiam ou ocorriam na área em baixa densidade, se tornam capazes de se reproduzir e, em especial, de ser polinizadas. Qual a estratégia reprodutiva que possibilitaria a sua localização pelo polinizador nestes locais recémcolonizados?

Grime (1983) aponta que a reprodução vegetativa é uma estratégia que ocorre em espécies colonizadoras, tornando-as capazes de se fixar e reproduzir nestes locais. Por outro lado, a hipótese sugerida é que as espécies pioneiras arbóreas devem possuir vários polinizadores, não especializados, o que aumentaria sua possibilidade de cruzamento.

A família Caricaceae apresenta quatro gêneros, incluindo Jacaratia, com espécies dióicas (Baker, 1976). Dentre estas, a pioneira J. dolichaula, típica de clareiras criadas pela queda de árvores, pode persistir em florestas maduras por vários anos após o fechamento do dossel (Bawa, 1980a).

Jacaratia spinosa é uma espécie arbórea de ampla distribuição geográfica (Correia, 1984); possui inflorescências masculinas axilares, pedunculadas, com flores pedunculadas amareloesverdeadas e cilíndricas (Reitz, 1970). As inflo- rescências femininas são axilares, unifloras, flores amarelo-esverdeadas, pedunculadas, cálice pentalobado, lobos carnosos, corola pentalobada, fendida até a base, ovário súpero, liso, pentalocular, multiovulado, com estilete curto e pentaestigmático (Reitz, 1970; Schultz, 1990).

Os objetivos deste trabalho são estudar a biologia da polinização de Jacaratia spinosa e relacioná-la com suas características dentro do processo de sucessão.

\section{MATERIAL E MÉTODOS}

As coletas foram realizadas entre agosto e novembro de 1991 na Mata de Santa Genebra, Campinas $\left(20^{\circ} 54^{\prime} \mathrm{S} ; 4^{\circ} 05^{\prime} \mathrm{W}\right)$, estado de São Paulo. Trata-se de um fragmento florestal de cerca de 250 ha, onde predomina floresta latifoliada subtropical semidecídua, cercada por áreas cultivadas e habitações humanas. Com médias anuais de temperatura de $22,4^{\circ} \mathrm{C}$ e pluviosidade de 1366,8 mm, há uma marcante estação quente e chuvosa de outubro a março e uma fria e seca de abril a setembro (Sazima, 1988).

Para localização dos indivíduos de Jacaratia spinosa e caracterização do padrão de florescimento, foram lançadas parcelas de $20 \mathrm{x}$ $10 \mathrm{~m}$ na direção $60^{\circ} \mathrm{N}$, distantes $50 \mathrm{~m}$ entre si.

A antese foi acompanhada em botões florais de inflorescências previamente marcadas, tendo sido efetuados registros do número de botões abertos em intervalos de 60 minutos.

O volume de néctar e concentração de açúcar foram determinados a partir de 20 inflorescências masculinas e cinco flores femininas previamente ensacadas. O néctar foi extraído das flores em intervalos de 60 minutos com capilares de 5 e $7 \mathrm{ml}$. A concentração de açúcar foi medida utilizando-se um refratômetro manual.

A viabilidade do pólen foi verificada através da montagem de lâminas coradas com carmim acético, tendo sido amostrados quatro estádios de desenvolvimento das flores: pré-antese, flor em antese, flor plenamente aberta e flor em senescência.

A receptividade do estigma foi testada em diferentes estádios de desenvolvimento da flor, utilizando-se água oxigenada 10 volumes.

Para detecção de glândulas de odor, as flores foram mergulhadas em solução de vermelho neutro $(1: 1000)$. O aroma foi analisado acondicionando-se flores em recipientes fechados. 
Os sistemas de reprodução (xenogamia, agamospermia) foram testados ensacando-se botões florais, comparados entre si e com flores deixadas expostas à visitação (controles).

Os visitantes foram estudados através de observações naturalísticas contínuas (Lehner, 1979) durante o mês de outubro de 1991, ao longo do dia e à noite até às 23 horas, prolongandose em uma ocasião, até às 02 horas, totalizando 70 horas de observações.

As observações noturnas foram efetuadas sob luz do luar ou com o auxílio de lanternas elétricas cobertas com filtro vermelho. Foram observadas duas plantas masculinas, sendo uma localizada fora da mata e a outra, na borda desta; e duas plantas femininas, localizadas na borda da mata e distantes cerca de 500 metros entre si, nas quais foram instaladas torres ( de 4 e $6 \mathrm{~m}$ de altura) de observação.

Para a descrição do comportamento dos visitantes, foram também efetuados registros fotográficos. Vários insetos foram capturados com puçá ou diretamente com frascos coletores, para identificação e constatação da presença de pólen.

\section{RESULTADOS E DISCUSSÃO}

As flores de Jacaratia spinosa apresentam diversas características que permitem incluí-las na síndrome de falenofilia (Faegri \& Van der Pijl, 1979): antese noturna, odor adocicado, cores sóbrias, forma tubular, pendentes, néctar encontrado em tubo longo (nas masculinas), ausência de guias de néctar e distanciamento entre as anteras e a fonte de néctar.

Foi constatado dimorfismo sexual no tamanho das flores (Fig. 1), o que Bawa \& Opler (1975) consideram um evento comum em espécies florestais tropicais, sendo que, em $70 \%$ delas, as femininas seriam maiores que as masculinas.

As flores masculinas de J. spinosa apresentam cálice pentalobado, tubo curto com $1 \mathrm{~mm}$ de comprimento, corola carnosa, tubulosa, pentalobada, com tubo externamente glabro e internamente piloso, com dez estames em dois verticilos de cinco, anteras extrosas com conectivo apendiculado. São tubulosas, ocorrendo em inflorescências pendentes, localizadas nas pontas dos ramos, na parte mais externa da copa. As pétalas apresentam coloração verde e os estames, verde-amarelada. As flores medem aproximadamente $20 \mathrm{~mm}$ e o tubo da corola, cerca de $9 \mathrm{~mm}$ de comprimento, com $2 \mathrm{~mm}$ de diâmetro.

As inflorescências femininas apresentam-se em grupos de 3 a 4 flores, no ápice dos ramos, medindo cerca de $20 \mathrm{~mm}$ de comprimento, com lobos estigmáticos de comprimento de cerca de $7,2 \mathrm{~mm}$ e diâmetro de 5 a $8 \mathrm{~mm}$.

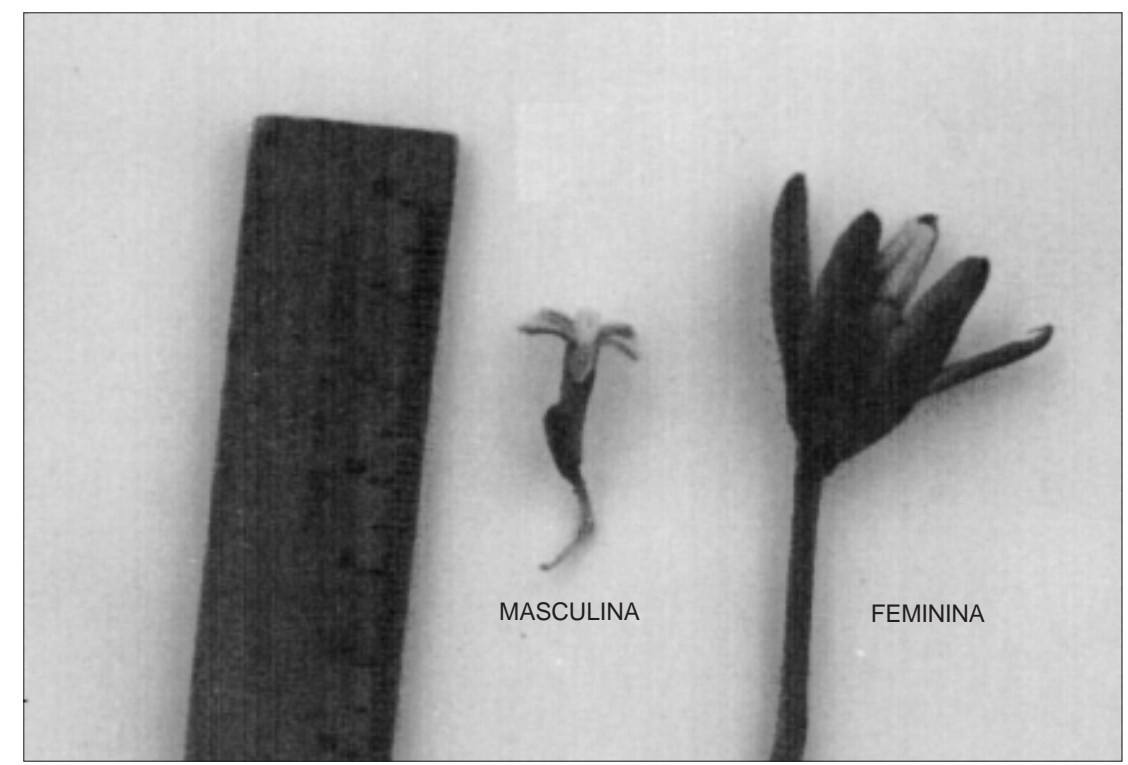

Fig. 1 - Flores masculina e feminina de Jacaratia spinosa. 
$\mathrm{Na}$ área inventariada, observou-se que $J$. spinosa ocorria de modo agregado, com as plantas distantes entre si, em média, cerca de $10 \mathrm{~m}$. Somente dois indivíduos foram constatados em floração, a $100 \mathrm{~m}$ entre si. A planta masculina localizava-se no interior da mata, a $23 \mathrm{~m}$ da bor$\mathrm{da}$, enquanto a feminina ocorria a $5 \mathrm{~m}$ da borda.

A distribuição espacial agregada é um padrão em espécies dióicas (Bawa \& Opler, 1975), como Carica cauliflora, Jacaratia dolichaula e J. spinosa (Badillo, 1967), sendo também uma característica de plantas pioneiras que ocupam grandes clareiras (Budowski, 1965). Em plantas com alta densidade, haveria uma menor especialização dos polinizadores (Feinsinger, 1983), e seriam favorecidos os polinizadores de pequeno porte como as abelhas, que podem apresentar movimentos interplantas menos distantes do que polinizadores de maior porte (Bawa \& Opler, 1975).

As plantas localizadas na borda da mata e em locais de maior insolação apresentaram florescimento mais intenso (sendo três masculinas e uma feminina), o que pode estar associado à menor competição por luz, água e nutrientes (Kageyama \& Piña-Rodrigues, 1993). A concentração de flores poderia atrair polinizadores ditos oportunistas, que visitam plantas com súbita e intensa oferta de flores (Handel, 1983), como pode ser o caso de $J$. spinosa, embora isso não tenha sido observado.

O período de florescimento da planta masculina foi mais extenso (52 dias) que o da feminina (22 dias), o que poderia ser resultado da competição entre plantas estaminadas (Bullock \& Bawa, 1981; Stephenson \& Bertin, 1983), comum em espécies dióicas tropicais (Opler \& Bawa, 1978; Bullock \& Bawa, 1981).

A proporção de plantas femininas e masculinas floridas durante o período de estudos foi de aproximadamente 1:1, embora isso não signifique necessariamente a proporção real intersexual na população, já que a maior parte dos indivíduos encontrava-se em estádio vegetativo. A proporção de flores femininas/masculinas foi de 1:30 (Tabela 1).

A mesma proporção de indivíduos masculinos e femininos floridos foi verificada em $J$. dolichaula por Bawa (1980b), enquanto a de flores foi de 1:16. Nesta última espécie, segundo o autor, ocorreria uma competição intersexual por polinizadores quanto ao número de flores, com as plantas masculinas produzindo maior quantidade de flores relativamente às femininas.

TABELA 1

Quantidade e proporção de indivíduos, flores femininas e masculinas e de frutos em Jacaratia spinosa.

\begin{tabular}{|c|c|c|c|}
\hline & $\begin{array}{c}\text { Plantas } \\
\text { femininas }\end{array}$ & $\begin{array}{c}\text { Plantas } \\
\text { masculinas }\end{array}$ & Proporção \\
\hline Indivíduos & 3 & 4 & $1: 1$ \\
\hline Flores & 146 & 4872 & $1: 30$ \\
\hline Frutos & 84 & - & - \\
\hline
\end{tabular}

O processo de antese das flores masculinas de $J$. spinosa pode ser descrito em três fases:

a) pré-antese, que ocorre após os botões florais atingirem aproximadamente $20 \mathrm{~mm}$ de comprimento, tendo a planta pré-floração imbricada, sendo visíveis septos longitudinais correspondentes à sobreposição das pétalas;

b) antese, quando duas pétalas se abrem, sendo rebatidas em direção à base da corola, até formarem um ângulo de 90 graus com o eixo longitudinal da flor. As anteras mantêm-se agregadas acima da superfície da flor, com filetes eretos. Tanto nesta fase quanto ainda em botões fechados, observou-se a presença de néctar e de pólen (flores funcionais). O processo de rebatimento das pétalas continua em direção à base da corola. Posteriormente, as pontas das pétalas tornam-se ligeiramente encurvadas;

c) senescência, quando as pétalas iniciam o processo de fechamento, até formarem um ângulo maior que 90 graus com o eixo longitudinal da flor. Na borda de cada pétala podem ser observados pontos de coloração marrom. Os filetes estão flácidos e a flor, menos túrgida.

Em cada inflorescência ocorrem flores em diferentes fases do processo de antese. Os botões, após atingirem tamanho próximo a $20 \mathrm{~mm}$, podem permanecer fechados por até 12 horas (fase a). Uma vez iniciada a antese (fase b), o processo é contínuo, transcorrendo de 3 a 4 horas até a abertura total da flor. A senescência (fase c) iniciase 24 horas após a abertura da flor.

A maioria das flores tem antese noturna, com picos de abertura entre 20 horas e 22 horas e outro a 01 hora, embora verifiquem-se alguns botões esporádicos em antese em diferentes horários do dia. 
As flores femininas duram aproximadamente 48 horas. A maior duração da flor feminina em estádio funcional aumenta a possibilidade de polinização. Sua antese também inicia-se normalmente às 22 horas, durando cerca de 1 hora e 30 minutos, podendo ser descrita em duas fases:

a) antese: quando os botões florais iniciam o processo de antese com a distensão e abertura de duas pétalas em direção ao pedúnculo da flor. Durante um intervalo de 1 a 2 horas, as demais pétalas iniciam processo semelhante, ficando totalmente abertas, recurvadas em direção ao pedúnculo. Os lobos estigmáticos mantêm-se unidos, eretos, com coloração verde-amarelada.

b) Estádio de senescência: as pétalas apresentam-se murchas, com pontos marrons ao longo da borda de um dos lados de cada pétala. $\mathrm{O}$ processo de senescência continua até que as pétalas caiam. Os lobos estigmáticos tornam-se escuros, tendendo à cor marrom.

O volume de néctar nas flores masculinas variou consideravelmente ao longo do dia, sendo que aparentemente entre 15 horas e 17 horas não houve produção. A quantidade média foi de $112,5 \mathrm{ml}$. A concentração de açúcares foi em média de $13,9 \%$, tendo variado ao longo do dia. Houve dois períodos nos quais a concentração de açúcar foi maior: um entre 6 horas e 8 horas e 30 minutos outro entre 18 e 21 horas (Fig. 2). As flores femininas não produziram néctar.

O pólen manteve-se viável em sua maioria (em média, 97,2\%) durante todo o tempo em que foi oferecido, e sua viabilidade não se alterou sensivelmente com a idade da flor (Tabela 2).

Em relação ao estigma, os resultados obtidos sugerem que o mesmo já se encontra receptivo, mesmo antes do início da antese, assim permanecendo até os últimos estádios da senescência.

Tanto flores masculinas como femininas exalam odor adocicado, mais intenso no início da noite e ao amanhecer. $\mathrm{O}$ vermelho neutro evidenciou padrões de coloração que correspondem aos septos longitudinais visíveis na pré-antese, o que provavelmente indica a localização das glândulas odoríferas. O mesmo odor presente em flores masculinas e femininas provavelmente contribui para aumentar a transferência de pólen entre os dois sexos, uma vez que o olfato é um dos sentidos mais importantes para os insetos (Barth, 1985).

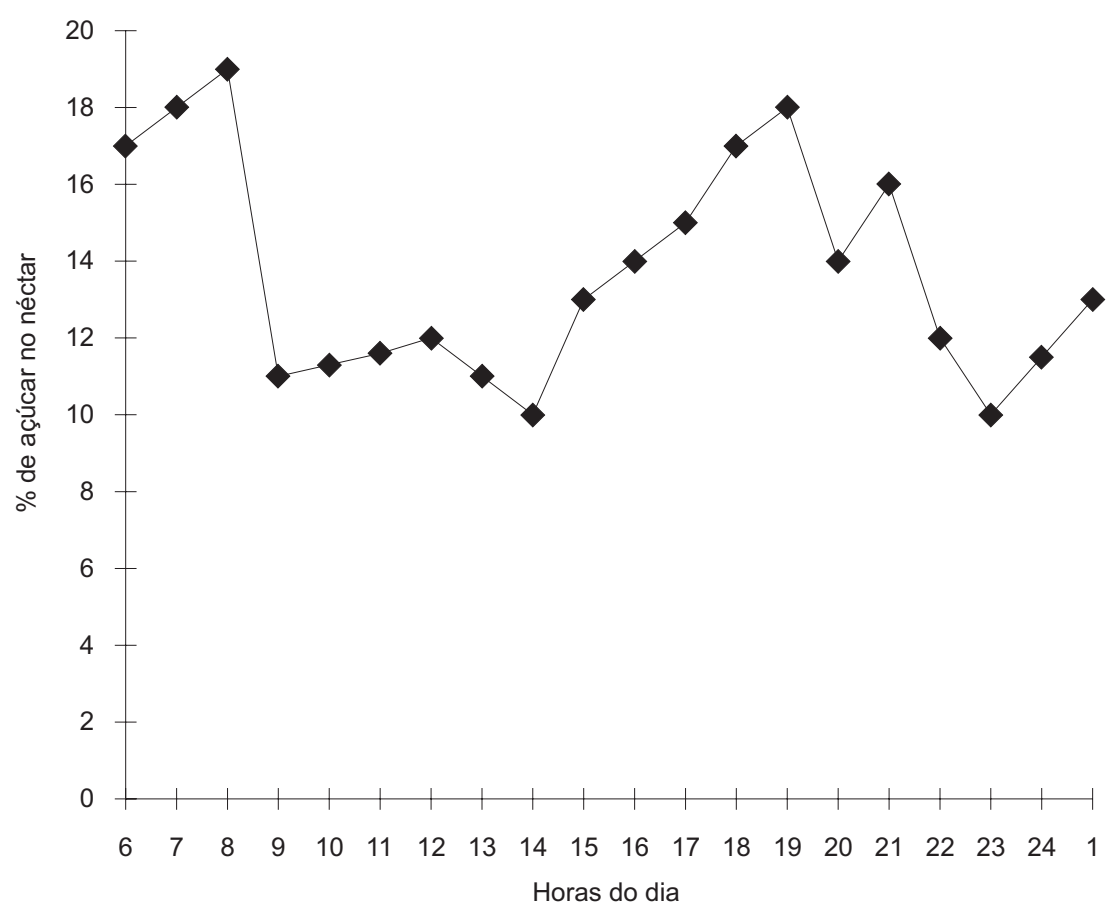

Fig. 2 - Variação na concentração de açúcar no néctar de Jacaratia spinosa ao longo do dia. 
TABELA 2

Viabilidade do pólen (\%) de Jacaratia spinosa em quatro fases de desenvolvimento das flores.

\begin{tabular}{|l|c|c|c|}
\hline Estádio & $\begin{array}{c}\text { Núm. } \\
\text { lâminas }\end{array}$ & $\begin{array}{c}\text { Média } \\
(\%)\end{array}$ & $\begin{array}{c}\text { CV } \\
(\%)\end{array}$ \\
\hline Pré-antese & 5 & 96,11 & 3,10 \\
\hline Início de antese & 4 & 95,87 & 5,91 \\
\hline Antese completa & 5 & 98,39 & 2,60 \\
\hline Senescência & 4 & 99,39 & 1,33 \\
\hline
\end{tabular}

Além do odor, as flores femininas e masculinas de J. spinosa têm em comum a cor e semelhanças morfológicas. Essas características levam os animais a visitarem as flores femininas que não lhes oferecem néctar. Além disso, as flores femininas mantêm-se funcionais por um longo período. Com a floração que se inicia posteriormente às árvores masculinas, as femininas seriam favorecidas pelo condicionamento dos visitantes, assegurando assim o sucesso reprodutivo.

De forma semelhante, Bawa (1980b, 1981) sugere que os polinizadores de Jacaratia dolichaula podem ser atraídos para a flor feminina por seu odor, cor e pela forma petalóide dos lobos estigmáticos, que mimetizariam a forma da flor masculina. O mimetismo de flores femininas é relatado em vários taxa (Gilbert, 1975; Bawa, 1977) e em outras espécies de Caricaceae (Baker, 1976; Bawa, 1980b).

O mimetismo pode ser inferido também para J. spinosa, uma vez que o estigma grande sugere a forma petalóide das flores masculinas, além das semelhanças de cor e odor entre flores dos dois sexos.

Semelhante ao observado no presente trabalho, Baker (1976), estudando Carica papaya (Caricaceae), propôs um modelo de polinização em que apenas as flores masculinas oferecem recursos (néctar) e as femininas são visitadas por "engano" ("mistake pollination"). Esse tipo de polinização pode ser um fenômeno muito difundido, particularmente onde os visitantes com baixa capacidade de discriminação das flores estão presentes.

Gilbert (1975) verificou que as flores femininas de Anguria umbrosa mimetizam as flores masculinas (mais numerosas) e são visitadas por "engano". Fatima C. M. Piña-Rodrigues (obs. pess.) também observou processo semelhante na espécie dióica Virola surinamensis (Miristicaceae), na qual apenas a flores femininas oferecem recursos alimentares a seus visitantes.

Pelos cruzamentos controlados, pôde-se verificar que houve formação de frutos tanto por agamospermia quanto por polinização cruzada (Tabela 3). Todos os botões marcados para controle formaram frutos, o que pode ser explicado pela alta eficiência do sistema de polinização e/ou pela ocorrência de agamospermia. Supondo que as sementes formadas por agamospermia sejam viáveis, esta seria uma maneira de garantir a reprodução, mesmo na ausência de polinizadores.

TABELA 3

Resultados dos cruzamentos controlados em Jacaratia spinosa.

\begin{tabular}{|l|c|c|c|c|}
\hline Tratamento & No & $\begin{array}{c}\text { Com } \\
\text { frutos }\end{array}$ & $\begin{array}{c}\text { Sem } \\
\text { frutos }\end{array}$ & $\begin{array}{c}\text { Sucesso } \\
(\%)\end{array}$ \\
\hline Fecundação cruzada & 5 & 2 & 3 & 40 \\
Agamospermia & 8 & 2 & 6 & 25 \\
Controle & 10 & 10 & 0 & 100 \\
\hline
\end{tabular}

Considerando-se que as pioneiras têm por característica a ocupação de novos ambientes, a especificidade de polinizador não seria desejável. A agamospermia proporcionaria para estas espécies um aumento na capacidade reprodutiva, possibilitando sua reprodução mesmo na ausência de polinizadores.

Os visitantes mais freqüentes às flores masculinas foram as borboletas, enquanto às femininas, as mariposas. Os beija-flores apresentaram a segunda maior freqüência de visitas nas masculinas e, nas femininas, as borboletas (Fig. 3).

Verificou-se a existência de dois picos de visitação nas flores masculinas, um entre 7 e 8 horas, representado principalmente por borboletas e beija-flores, e outro entre 19 horas e 20 horas, protagonizado pelas mariposas. Estes picos coincidiram com os horários de maior concentração de açúcar no néctar. Nas flores femininas, também caracterizou-se a existência de dois picos de visitação, um pela manhã, entre 8 horas e 9 horas e outro à noite, às 20 horas (Fig. 4).

Nas flores masculinas foram registradas visitas de seis espécies de mariposas. Aelopus titan aproximava-se das inflorescências masculinas em vôo direto. A seguir, orientava-se para uma flor e, adejando defronte a ela, introduzia por diversas vezes sua probóscide no interior da corola, quando 
podia receber pólen. A seguir, recuava, podendo visitar novamente a mesma flor, outras flores ou abandonar o local. As demais mariposas pousavam nas flores para visitá-las, podendo receber pólen em toda a região das peças bucais. Mariposas maiores podiam contatar as anteras com a porção distal de seu abdômen. O acúmulo de pólen nas mariposas é facilitado pela abundância de pêlos no corpo e nas pernas de muitas espécies e pela estrutura de sua probóscide (Faegri \& Van der Pij1, 1979).

As flores femininas foram visitadas por sete espécies de mariposas, sendo que apenas três foram também observadas em flores masculinas. Os visitantes aproximavam-se das flores em vôo irregular e pousavam orientados para o estigma, agarrando-se neste com as pernas ou, no caso das mariposas maiores, com as pernas anteriores e médias no estigma e posteriores em uma das pétalas. A seguir, tateavam com a probóscide por entre os lobos estigmáticos, contatando-os. Podiam também caminhar sobre o estigma, descrevendo movimentos circulares. Nesta ocasião, podia ocorrer a deposição de pólen na superfície estigmática.
Além de a olfação ser um órgão do sentido importante para as mariposas, à curta distância a visão e o tato tornam-se relevantes, sendo que a probóscide pode ser utilizada para tatear o recurso (Brantjes \& Bos, 1980), conforme se verificou no presente estudo. Assim sendo, o mimetismo de cor, forma e odor anteriormente discutidos aplicar-se-ia a estes insetos.

Quatro espécies de borboletas visitaram flores masculinas e femininas, embora 17 espécies tenham sido observadas visitando as masculinas e 5, as femininas. A mais freqüente foi Ascia monusta. Borboletas podem ser condicionadas a discriminar cores e formas associadas a recursos como o néctar. Além disso, são capazes de retornar à fonte de recursos com alto grau de regularidade (Swihart, 1971 apud Gilbert, 1975). Segundo Faegri \& Van der Pijl (1979), são também capazes de distinguir odores, embora as borboletas tenham um sentido olfativo menos acurado que as mariposas.

O comportamento de visitação foi bastante semelhante ao descrito para as mariposas. Desta forma, as espécies que visitaram tanto flores

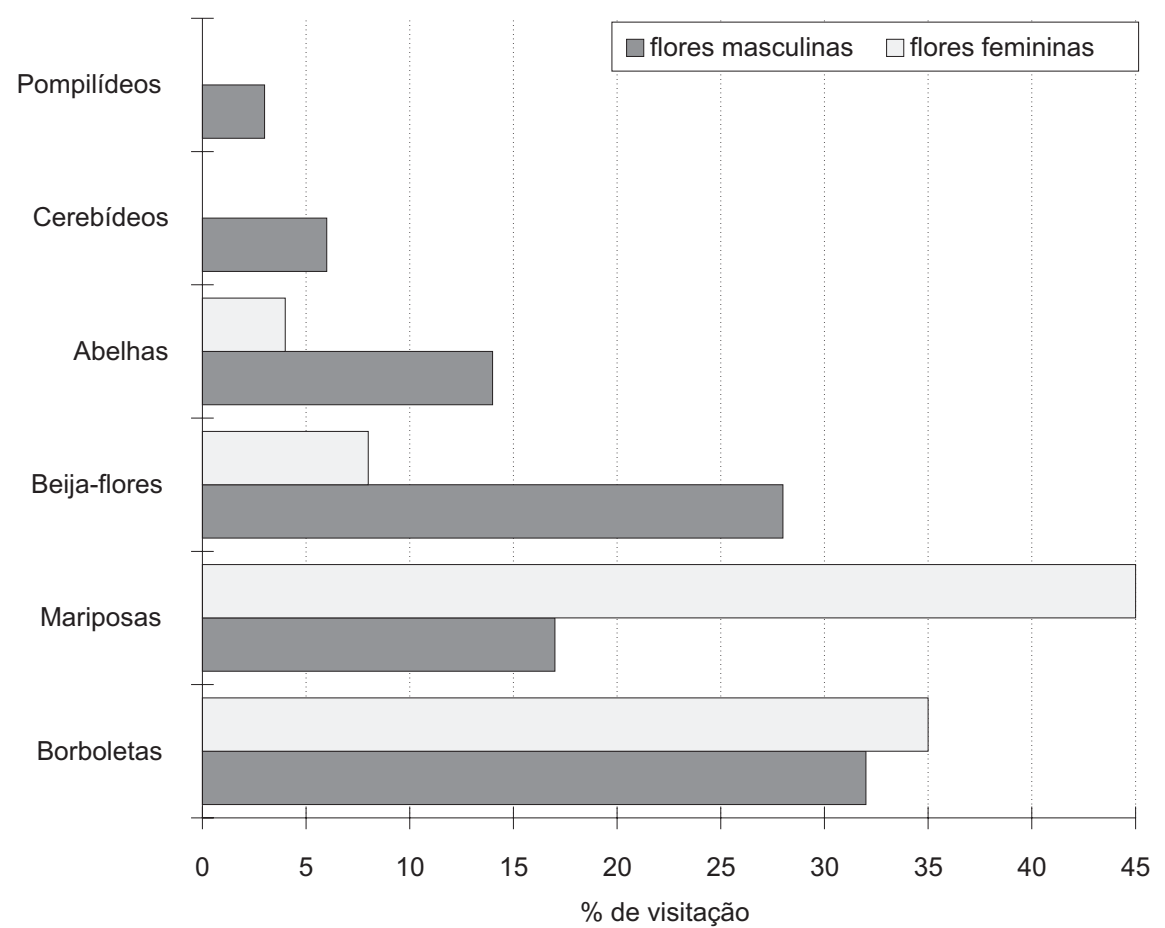

Fig. 3 - Visitantes mais freqüentes às flores de Jacaratia spinosa. 


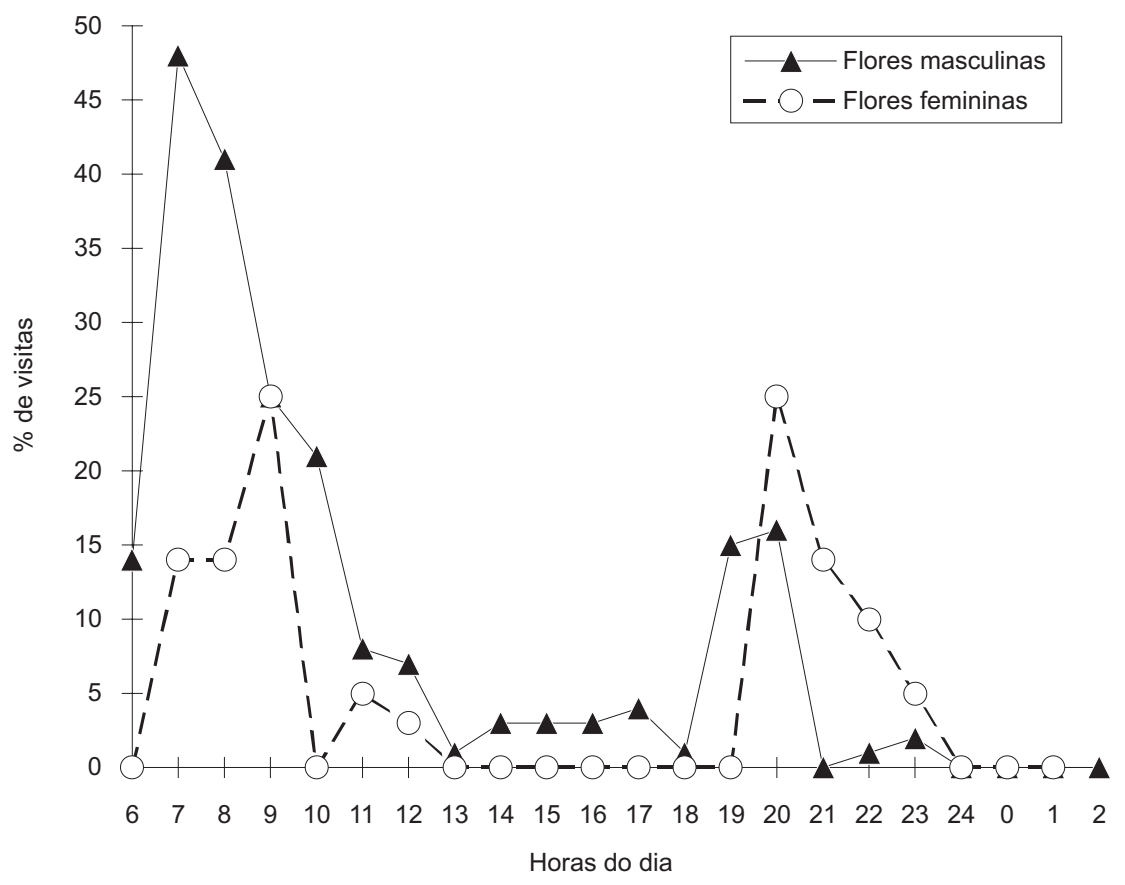

Fig. 4 - Horários de visitação às flores masculinas e femininas de Jacaratia spinosa.

masculinas quanto femininas são polinizadores potenciais de Jacaratia spinosa.

Dentre as abelhas, detectou-se visitas de Apis mellifera e Trigona spp. às flores masculinas, enquanto Xylocopa sp. visitou flores de ambos os sexos esporadicamente.

Marimbondos (Pompilidae) visitaram raramente flores de ambos os sexos, contatando anteras e estigma, podendo ser citados como eventuais polinizadores. Um indivíduo capturado apresentava pólen no abdômen.

Entre as aves, constataram visitas dos beija-flores Eupetomena macroura, Amazilia lactea, Amazilia versicolor e Chlorostilbon aureoventris praticamente apenas nas flores masculinas, comportando-se como pilhadores de néctar (Piratelli, 1993). Dois Passeriformes, Coereba flaveola e Dacnis cayana também visitaram somente flores masculinas, derrubando muitas flores ao caminhar sobre as inflorescências. Este comportamento pode ser caracterizado como pilhagem de néctar (Inouye, 1980).

As plantas que dependem de animais especialistas e de grande porte (aves e mamíferos) para a polinização são mais freqüentemente encontrados em estádios sucessionais mais maduros (Feinsinger et al., 1987). Pelo seu comportamento de colonizadores de ambientes recém-perturbados, é esperado que plantas pioneiras venham a ter como polinizadores diversos animais pouco especializados.

De fato, conforme se observou, embora $J$. spinosa esteja associada à síndrome de falenofilia, as borboletas e, em menor intensidade, pompilídeos e abelhas podem participar de seu processo de polinização.

Mesmo na ausência de polinizadores, a espécie apresenta capacidade de se reproduzir vegetativamente. Sob o aspecto da polinização, a espécie comporta-se então como uma planta pioneira.

Agradecimentos - Os autores agradecem aos Profs. Drs. Ivan e Marlies Sazima (Universidade Estadual de Campinas), pela leitura e críticas à primeira versão do manuscrito; Prof. Dr. Keith S. Brown Jr. (Universidade Estadual de Campinas), pela identificação dos Lepidópteros; aos funcionários da Mata de Santa Genebra, em especial aos Srs. Valdivino e Roberto, pela inestimável ajuda durante os trabalhos de campo; à Fundação José Pedro de Oliveira, por permitir os trabalhos na Mata de Santa Genebra; à Escola Superior de Agricultura Luiz de Queiroz (USP), pela cessão das torres de observação e equipamentos; ao Depto. de Biologia Vegetal da Universidade Estadual de Campinas, pelos equipamentos. 


\section{REFERÊNCIAS BIBLIOGRÁFICAS}

BADILlO, V. M., 1967, Esquema de las Caricaceaes. Agronomia Tropical, 17: 245-271.

BAKER, H. G., 1976, "Mistake" pollination as a reproductive system with special reference to the Caricaceae, pp 161-169. In: J. Burley \& B. T. Styles (eds.), Tropical trees: variation, breeding and conservation. Academic Press, London.

BARTH, F. G., 1985, Insects and flowers: the biology of a partnership. Princeton University Press, Princeton.

BAWA, K. S., 1974, Breeding systems of trees species of a lowland tropical community. Evolution, 28: 85-92.

BAWA, K. S., 1979, Breeding systems of trees in a tropical wet forest. New Zeal. J. Bot., 17: 521-524.

BAWA, K. S., 1980a, Evolution of dioecy in flowering plants. Ann. Rev. Ecol. Syst., 11: 15-39.

BAWA, K. S., 1980b, Mimicry of male by female flowers and intrasexual competition for pollinators in Jacaratia dolichaula (D. Smith) Woodson (Caricaeae). Evolution 34(3): 467-474.

BAWA, K. S., 1981., Jacaratia dolichaula (Papaya Silvestre, Papaya de Venado, Wild Papaya). Species Accounts, 1: 264-265.

BAWA, K. S. \& OPLER, P. A., 1975, Dioecism in tropical forest trees. Evolution, 329: 167-179.

BRANTJES, N. B. M. \& BOS, J. J., 1980, Hawkmoth behaviour and flower adaptation reducing self pollination in two liliiflorae. New Phytol, 84: 139-143.

BUDOWSKI, G., 1965, Distribution of tropical american rain forest species in the light of successional process. Turrialba 15(1): 40-42.

BULLOCK, S. H. \& BAWA, K. S., 1981, Reproductive biology of tropical lowland rain forest trees. I. Sexual systems and incompatibility mechanisms. Am. Jour. Bot., 72: 331-445.

CORREIA, M. P., 1984, Dicionário das plantas úteis do Brasil e das exóticas cultivadas. IBDF, Brasília, Vol. 4.

CROAT, T. B., 1979, The sexuality of the Barro Colorado Island flora (Panama). Phytologia, 42: 319-48.

FAEGRI, K., \& VAN DER PIJL, L. 1979. The Principles of Pollination Ecology. Sinauer Associates, London, 224p.

FEINSINGER, P., 1983, Coevolution and pollination, pp. 282-310. In: D. Futuyma \& M. Slatkin, Coevolution, Sinauer Associates Inc Publishers, Sunderland.

FEINSINGER, P., BEACH, J. H., LINHART, Y. B., BUSBY, W. H. \& MURRAY, K.G., 1987, Disturbance, pollination predictability, and pollination success among costa rican cloud florest plants. Ecology, 68(5): 1294-1305.
GILBERT, L. E., 1975, Ecological consequence of a coevolved mutualism between butterflies and plants, pp. 210-240. In: L.E. Gilbert \& P. H. Raven (eds.), Coevolution of animals and plants, University of Texas Press, Austin.

GRIME, J. P., 1983, Plant strategies and vegetation processes. John Wiley \& Sons, N. York, 222p.

HANDEL, S. N., 1983, Pollination ecology, plant population structure, and gene flow, pp. 163-211. In: L. Real (ed.), Pollination biology, Academic Press, Orlando.

INOUYE, D. W., 1980, The terminology of floral larceny. Ecology, 61(5): 1251-1253.

KAGEYAMA, P. Y. \& PIÑA-RODRIGUES, F. C. M., 1993, Fatores que afetam a produção de sementes, pp. 19-46. In I. B. Aguiar; F. C. M. Piña-Rodrigues \& M. B. Figliolia (eds.), Sementes florestais tropicais, ABRATES, Brasília.

LEHNER, P., 1979, Handbook of Ethological Methods, Gardland STPM Press, New York.

MARTÍNEZ-RAMOS, M., 1985, Claros, ciclos vitales de las arboles tropicales y regeneración natural de las selvas altas perenifolias. In: A. Gomez-Pompa \& S. Del Almo (eds.), Investigaciones sobre la regeneración de selvas altas em Meracruz, Mexico, Volumen II, INIREB Editorial Alhambra Mexicana Xalapa, Mexico, 421p.

OPLER, P. A., \& BAWA, K. S., 1978, Sex ratios in tropical forest trees. Evolution, 32: 812-821.

PIRATELLI, A. J., 1993, Comportamento alimentar de beijaflores em Inga spp. (Leguminosae, Mimosaceae) e Jacaratia spinosa (Caricaceae) em mata residual do sudeste brasileiro. IPEF, 46: 43-51.

REITZ, P. R., 1970, Flora ilustrada catarinense. CNPq, Brasília, 22p.

SAZIMA, I., 1988, Um estudo da biologia comportamental da jararaca, Bothrops jararaca com uso de marcas naturais. Mem. Inst. Butantan, 50(3): 83-99.

SCHULTZ, A., 1990, Introdução à botânica sistemática. Sagra, Porto Alegre, Vol. 2.

STEPHENSON, A. G. \& BERTIN, R. I., 1983, Male competition, female choice and sexual selection in plants, pp. 110-151. In: L. Real (ed.), Pollination biology, Academic Press INC, Orlando.

ZAPATA, T. R. \& ARROYO, M., T. K., 1978, Plant reproductive ecology of a secondary deciduous tropical forest in Venezuela. Biotropica, 10(3): 221-230. 